\title{
Market timing using derivatives on the Johannesburg Stock Exchange during bear periods
}

\author{
Marc Dumont de Chassart, Colin Firer*, Wendy Grantham, Simon Hill, \\ Mark Pryce \& lan Rudden \\ School of Management Studies. University of Cape Town, Private Bag. Rondebosch 7701. South Africa
}

cfireracommerce.uct.ac.za

Received March 2000

\begin{abstract}
The objective of the study was to investigate the gains from market timing strategies using derivatives during a period when the return on the market was below that of the risk-free asset (a so-called bear period). It was found that perfect timers appear to do better under bullish rather than bearish markets. However, in a bear period, substantially lower predictive accuracies were needed to beat a buy and hold strategy when timing strategies using call options and holding cash (bull timing) were used compared to the strategy of holding the market and buying puts (bear timing) ahead of anticipated poor periods. Finally both the strategies of holding cash and buying a call in every period (market speculation) as well as of holding the market and buying a put in every period (portfolio insurance) out-performed a buy and hold strategy.
\end{abstract}

* To whom all correspondence should be addressed.

\section{Introduction}

Around the world investors engage in strategies such as market timing in order to try and beat the market. Market timing involves forecasting whether the stock market will rise or fall over a particular period and then attempting to profit from such predictions. In traditional market timing investors hold the market index if they expect a market upturn and switch to a 'riskless' asset when a market downturn is expected. Implementing such a strategy on the Johannesburg Stock Exchange (JSE) may be difficult because of relatively high transactions costs and liquidity considerations.

One of the earliest studies of market timing was that of Treynor \& Mazuy (1966). They compared the performance of mutual funds to that of the market in order to gauge the timing abilities of the fund managers and found that there was no evidence to indicate that any of the funds outperformed the market due to successful timing strategies. Research done by Sharpe (1975) showed that the potential gains from a successful timing strategy are large. but that investors needs to be more than $70 \%$ accurate in timing to realise any benefit over a buy-and-hold strategy.

It was with Jeffrey's study (1984) that an approach to market timing issues was developed which looked at the potential returns obtainable at various levels of predictive accuracy. Jeffrey calculated returns on an annual basis over the period 1926 to 1982 . He found that the annualised real return on the market (S\&P 500) was 6\%. With $100 \%$ accurate timing the return could be boosted to $12 \%$. However, with completely inaccurate timing the return fell to $-6 \%$.

Jeffrey then examined accuracy levels in prediction from $50 \%$ to $75 \%$. His conclusion was that the possibility of underperforming the market was greater than the possibility of outperforming the market at almost all accuracy levels in the range. with the exception of accuracy levels at the top of the range.

Firer, Ward \& Teeuwisse (1987) repeated Jeffrey's (1984) research on the JSE. In addition to the accuracy levels of
$100 \%$ and $0 \%$, they defined levels of accuracy where the timing strategy always outperformed the market, where the strategy always yielded a lower return than the market, and where there was equal probability of performing better or worse than a buy-and-hold strategy.

The average annual buy-and-hold return using quarterly timing for the period 1967 to 1986 was $19 \%$. $100 \%$ accurate timing would increase the retum to $32 \%$, while the worst return possible was $-2.0 \%$. Altogether $34 \%$ accuracy would always result in poorer performance than the buy-and-hold, and at an accuracy of $66 \%$ there was an equal chance of over- or under-performance relative to the buy-and-hold strategy. The average accuracy level required to ensure that a timing strategy always produced superior return was found to be rather stringent at $85 \%$. Similar results were obtained in an updated study (Firer, Sandler \& Ward, 1992).

These studies clearly show that for a market timing strategy to beat a buy-and-hold strategy exceptional predictive accuracy is required. This led Firer et al. to conclude that

'the achievement of superior returns requires a forecasting ability well above that which would be obtained from a random switching process' (1987).

Kester (1990) studied the effect of transactions costs on a traditional market timing strategy. His study showed timing strategies produced lower returns under all review periods as the transaction costs increased. This was particularly in evidence as the review period decreased. Required prediction ability rose from percentages in the high $50 \mathrm{~s}$ and $60 \mathrm{~s}$ to as much as $86 \%$ as transaction costs moved from $0.25 \%$ to $2 \%$ per switch. Again it was the monthly figures where the effect was greatest, and the largest ranges were observed.

A buy-and-hold strategy has in effect a $100 \%$ accuracy in forecasting bull markets and a $0 \%$ accuracy in forecasting bear markets. Investors therefore are in the market in every bull period (as they would like) but also are exposed to every bear period (which they would prefer to avoid). The effect of differentiating between bull and bear timing accuracies 
determines whether the below-average returns from timing are due to an inability to avoid bear markets or the failure to catch bull runs by staying out of the market for too long.

Chua, Woodward \& To (1987) conclude that the accuracy in forecasting bull markets is the variable deciding whether timing will pay off. If investors only have a $50 \%$ chance of correctly forecasting bull markets then they should not participate in market timing at all, even if they can forecast bear markets perfectly. If their forecasting ability is over $\mathbf{8 0 \%}$ for bull markets, their average extra return will be positive even if they cannot forecast bear markets at all. Investors will on average be likely to spend too long in Treasury bills and thus miss the bull periods that generally follow directly afterwards. As a result their average return will be less than the buy-and-hold return. A study by Droms (1989) showed similar results.

With the introduction of derivative instruments into the investment arena, doors have been opened for more effective risk management as well as for a variety of new investment strategies. Derivatives can be utilised in market timing so as to combat problems such as liquidity associated with a traditional timing strategy. By using derivative instruments the risk profile of a portfolio can be rapidly changed without having to trade in the underlying asset.

However, the real benefit of using derivatives in a market timing strategy is the ability to engage in both bull and bear timing, which is not possible using the traditional timing approach. In a bull timing strategy investors hold Treasury bills and purchase at-the-money call options on the market index when it is predicted that the market will rise. In a bear timing strategy investors hold the index and purchase at-the-money put options on the market index when it is predicted that the market will decline. Alternatively investors could purchase an option on the index future contract as opposed to the option on the index itself.

Research done by Waksman, Sandler, Ward \& Firer (1997) on the JSE using derivatives indicated that the returns obtained from market timing could be greater or less than that of a traditional timer depending on the predictive accuracy of the timer. Their results indicated that for perfect predictive accuracy, returns would be on average $3 \%$ lower than traditional timing using annual review periods and 5-8\% lower for monthly review periods. However at the lower levels of predictive accuracy option timing was far more beneficial than traditional timing. For bear timing with a $0 \%$ accuracy, returns were $10 \%$ higher than that of traditional timing. Similarly for bull timing, returns of at least $4 \%$ would have been realised compared to negative returns using traditional timing.

The reason for this is that total transactions costs for the perfect traditional timer were less than the costs of the options for the perfect option timer. At the other extreme, incompetent traditional timers would always find themselves in the wrong asset, thus being penalised by the difference in returns between the two assets. Option timers will, however, only be penalised to the extent of the cost of the options, which is often less than the penalty suffered by incompetent traditional timers.

Portfolio insurance is an additional strategy that can be used to hedge the risk of the portfolio. Portfolio insurance is similar to the protective put strategy where the index is held and a put is purchased on the index. The difference is that with portfolio insurance, a put is purchased in every review period. This provides the investor with unlimited upside potential and the downside is limited to the cost of the option.

Research done by Hanson (1984) on the NYSE showed that the protective put strategy provides very good returns on the NYSE. The data that was used consisted of an S\&P500 index and 3-month European put options over the period 1970 1983. He showed that by holding the S\&P500 index and purchasing a 3-month at-the-money European put option in every quarter, investors would have received returns of $2 \%$ per annum in excess of that provided by a buy-and-hold strategy. A $2.2 \%$ average quarterly premium was incorporated into the data. The results were generated during a period where the market was rising and the strategy would thus also be a viable option in a market that was falling.

Waksman et al.'s (1997) results were contrary to those of Hanson (1984). He found that in the South African market over the period 1963-1992, portfolio insurance yielded a return that was $3.1 \%$ less than a buy-and-hold strategy over the same period. Waksman et al. observed that,

'It is expected that the beta (or systematic risk) of the insured portfolio is less than that of the market beta of equity. As a result, the risk adjusted returns may prove to be more appealing' (1997).

A similar strategy called market speculation involves holding a riskless asset and purchasing a call option on the index for every review period. Research by Waksman et al. (1997) indicated that market speculation was a more profitable strategy than engaging in bull timing. Market speculation showed an annualised return of $15 \%$ for the period. In order for bull timers to beat this return, they would have to possess superior predictive abilities and would need an accuracy of close to $90 \%$ for a sure gain and $75 \%$ for an equal chance of beating market speculation. Market speculation showed a better return than that of Treasury bills but would not have beaten the index during the study period.

The results for market speculation corresponded to the results of portfolio insurance because the risk profile of the portfolio in market speculation is identical to that of portfolio insurance. 'On the upside the portfolio has a beta of one, on the downside the portfolio has a beta of zero less the cost of the option premium' noted Waksman et al. (1997).

Past research on market timing covered bull periods where the market out performed the riskless asset. However this is not always the case. For the period 1990 to 1998 the return on the ALSI index was $10.2 \%$ per annum compared to that of the three-month Treasury bill which yielded a return of $15.1 \%$ per annum. This could be described as a bear period. Such a period has a profound effect on the return of the buy-and-hold strategy and thus, since this value is considered to be the target to beat, it was felt that a timing strategy could out perform the market under these conditions.

The objective of this study was to investigate the possible gains from several market timing strategies during a bear period on the JSE. In particular returns from market timing using the following strategies over monthly, quarterly and annual review periods were compared to a buy-and-hold strategy: 
- Bull timing by holding cash and buying calls either on the index or on the index futures contract when market upturns are expected.

- Market speculation by holding cash and buying calls either on the index or on the index futures contract in all review periods.

- Bear timing by holding the index and buying puts either on the index or on the index futures contract when market downturns are expected.

- Portfolio insurance by holding the index and buying puts either on the index or on the index futures contract in all review periods.

\section{Methodology}

The All Share Index (ALSI) was used to proxy a welldiversified portfolio. The change in index value was combined with the dividend yield on the index to calculate holding period returns. The three-month Treasury bill rate, converted to a yield, was used as the riskless asset. Futures prices on the ALSI were used in order to calculate options prices on the index future. All data was sourced through INetBridge.

Option prices were calculated using appropriate models since the required data on option prices was not available. The variables ALSI, dividend yield on the ALSI and the yield on the Treasury bills were used to calculate European at-themoney call option prices on the index using the Black-Scholes formula. This formula was adjusted using the Merton adjustment (Gemmill, 1993) to incorporate dividends. For call option prices on the future on the index no adjustment was made. To value the put premiums, the standard put-call parity theorem was used.

According to Galai (Brenner, 1983), the Black-Scholes option pricing model is a good approximation of market prices for at-the-money options of medium- and long-term maturities. The dividend adjustment model is more robust if the dividends are paid continuously over time. Having the index as the underlying asset causes dividends to accrue on a regular basis since each company in the index declares and pays dividends at a different time. These factors make the models robust for the purpose of this study.

The historical volatility, computed using monthly spot prices on the index for the preceding twelve months, was calculated using the maximum likelihood estimator.

In calculating the volatility of the futures contracts it was discovered that, in most cases, the contracts did not trade long enough for a reliable past history of retums to be available. In order to overcome this problem, volatilities calculated on the index were used as proxies for the futures contracts volatilities. Simple F- \& t-tests showed that the volatilities of the two underlying assets (futures contract and index) were not statistically different.

The following strategies were analysed:

- Bear Timing using European Put Options on the ALSI;

- Bull Timing using European Call Options on the ALSI;

- Bear Timing using European Put Options on the Future on the ALSI;

- Bull Timing using European Call Options on the Futures on the ALSI.

In order to achieve perfect hedges or perfect speculations it was assumed that fractions of options could be purchased.

If investors are bear timing and predict that the market will rise, then their portfolio will consist of the index only and the return will be the sum of the return on the index $\left(H P R_{c}\right)$ plus the dividend retum $\left(\mathrm{HPR}_{\mathrm{d}}\right)$. The dividend retum is calculated as the dividends received over the period divided by the starting index value. This return is achieved whether the market rises or falls.

However if the investors believe that the market will fall and purchase put options for protection then, due to the asymmetrical payoff of options, the return is dependent on whether the market rises or falls. If the forecast is correct and the market does decline then the payoff of the portfolio is:

- $\mathrm{HPR}_{\mathrm{c}}+\mathrm{HPR}_{\mathrm{d}}$ for the index held;

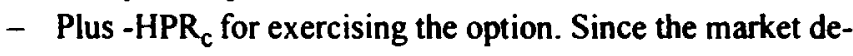
clined, the gain on the option will be equal to the fall in the market. A minus sign is used to obtain the correct (positive) return.

- Less the cost of the options. This is denoted as a percentage of the index portfolio (\%Put) to achieve the correct cost for all the options purchased.

If in fact the market actually rose and the investors were incorrect then the return would be the same as above except for the gain on the option $\left(-\mathrm{HPR}_{\mathrm{c}}\right)$. It is assumed that the investors borrowed short-term, at the risk-free rate (denoted HPR, which is the return on the Treasury bills), to finance the cost of the put. Panel A of Table 1 shows the retums for each possible outcome.

Panel B of the table illustrates the returns available to bull timer. If investors are bull timing and predict that the market will decline, then their portfolio will consist of Treasury bills

Table 1 Returns of all possible outcomes for bear and bull timing strategies using options

\begin{tabular}{|c|c|c|}
\hline \multicolumn{3}{|c|}{ Panel A Bear timing } \\
\hline & Correct decision & Incorrect decision \\
\hline Bull period & $H P R_{c}+\mathrm{HPR}_{\mathrm{d}}$ & {$\left[1+H P R_{c}+H P R_{d}-\% P u t\left(1+H P R_{r}\right)\right]-1$} \\
\hline Bear period & {$\left[1+H P R_{c}+H P R_{d}-H P R_{c}-\% P u t\left(1+H P R_{r}\right)\right]-1$} & $H P R_{c}+H P R_{d}$ \\
\hline \multicolumn{3}{|c|}{ Panel B Bull timing } \\
\hline & Correct decision & Incorrect decision \\
\hline Bull period & {$\left[H P R_{c}+(1-\%\right.$ Call $\left.)\left(1+H P R_{T}\right)\right]-1$} & $\mathrm{HPR}_{\mathrm{r}}$ \\
\hline Bear period & $\mathrm{HPR}_{\mathrm{r}}$ & {$\left[(1 \cdot \%\right.$ Call $\left.)\left(1+H P R_{1}\right)\right] \cdot 1$} \\
\hline
\end{tabular}


only and the return will be the holding period return for the bills (denoted HPR, ).

However, if the investors believe that the market will rise and purchase call options to speculate then, due to the asymmetrical payoff of options, the return is dependent on whether the market rises or falls. If the forecast is correct and the market does rise then the payoff of the portfolio is as such:

- HPR for the Treasury bills held;

- Plus HPR for exercising the option. The gain on the option will be equal to the gain of the market

- Less the cost of the options. This is denoted as a percentage of the index portfolio (\%Call) to achieve the correct cost for all the options purchased.

If in fact the market actually declined and the investors were incorrect, then the return would be the same as above except for the gain on the option (HPR $)$. To finance the call premium it is assumed that the investors liquidate part of their cash portfolio. This liquidation has the same effect on the cash portfolio that the borrowing had on the index portfolio.

A $100 \%$ perfect timing is achieved when in each review period investors make decisions that result in the portfolio achieving the highest possible return. In certain periods this will require purchasing options to hedge or speculate, depending on the strategy and prediction.

As the investors' ability to predict the market decreases they will find themselves incorrectly positioned in the market thus realising less than optimal results. The impact of the incorrect decision is dependent on the marginal difference in returns between the 'correct' and 'incorrect' portfolios. When one incorrect decision is made by investors then they will miss, in the worst case, the period in which the marginal difference between the returns is the greatest, or will miss, in the best case, the period where the difference is the least.

As the forecasting accuracy declines, the number of incorrect selections increases. The best and worst cases at each predictive accuracy can be calculated by ranking the differences between the 'correct' and the 'incorrect' portfolio returns and allocating the large differences to the worst case scenario and the smallest differences to the best case scenario.

The potential range of returns achievable through market timing was evaluated using an Excel spreadsheet. In order to calculate the maximum possible return from perfect timing, the asset with the highest return was chosen each period, thus emulating the behaviour of the investor who has perfect predictive abilities. The annualised compound average return, after switching costs, was calculated.

The returns obtained when forecasting ability is less than perfect were then established. For each period there are two possible retums, one for each of the assets under consideration. If the investor only incorrectly forecasts one of the periods, the final return from the timing strategy will depend on which period is the one in which the incorrect forecast is made. In some periods there will be minimal differences between the returns of the two assets, so the penalty for error is small. In other periods it may be correspondingly large. Thus a set of $N$ returns (where $N$ is the number of forecast periods in the study) can be calculated based on making a single error.

As the success rate decreases, all $\mathrm{N}$ possible outcomes for each accuracy level will lie between two lines - the best case line, where the error/s made have the least impact on final re- turns, and the worst case line, where the impact is greatest. A 'football' shaped graph of returns first described by Jeffrey (1984) (Figure 1) is thus generated. A more detailed discussion of the graph may be found in Firer, Gray, Sandler \& Ward (1996). Graphs were calculated for both bull and bear timing.

Superimposed on the 'football' are the returns that could have been achieved by buying and holding the ALSI index, buying and holding Treasury bills, engaging in market speculation and in portfolio insurance.

These graphs are then analysed and compared across the different timing strategies and review periods. Five key points on the football are assessed:

1. The return from $100 \%$ accuracy - Perfect Timing

2. The return from $0 \%$ accuracy - Imperfect Timing

3. The predictive accuracy level above which market timing always yields a higher return than a buy-and-hold the index strategy.

4. The predictive accuracy level below which market timing always yields a lower return than a buy-and-hold the index strategy.

5. The predictive accuracy level at which there is an equal probability that market timing will yield a higher return than a buy-and-hold the index strategy.

\section{Results}

As previously noted the period $1^{\text {st }}$ January 1990 to $31^{\text {st }}$ December 1998 was largely a bear run with the ALSI providing a return of $10.2 \%$ compared to $15.1 \%$ for Treasury bills. This had a profound effect on the results, especially with option timing.

\section{(a) Traditional timing}

The results from traditional timing are similar to results shown from previous studies. The gains that a perfect market timer can achieve are superior to the returns from a simple buy-and-hold strategy. Using quarterly timing as a benchmark it can be seen (Table 2) that investors with $100 \%$ accuracy would have earned a return of $26.2 \%$ compared with the $15.1 \%$ return from Treasury bills and the $10.2 \%$ return from the Index. However, the loss that the incompetent market timers would have sustained is $-5.5 \%$,

Waksman et al. (1997) reported that over the period 19631992, 100\% accurate timing achieved a return of $43.2 \%$ for monthly timing compared to $34.1 \%$ found here (for $100 \%$ inaccurate timing, $-22.07 \%$ compared to $-19.4 \%$ ). The reason for these differences is due to the poor performance of the market from 1990 to 1998 .

Again, as a result of the poor performance of the index, the required predictive accuracy in order to guarantee a better result than holding the index is only $63.3 \%$ for annual timing This is far lower than the $90.7 \%$ reported by Waksman et al. (1997). For an equal chance of achieving a higher return than holding the index, a $38.3 \%$ predictive accuracy is required, a figure substantially lower than Waksman et al.'s result $(78.7 \%)$. For predictive accuracies below $21.5 \%$ a sure loss will be made (49.0\% - Waksman et al., 1997).

Waksman et al. (1997) calculated a return of $18.3 \%$ per an num for a buy-and-hold strategy. Had the returns on the market during the period studied been of this order, predictive 
Table 2 Returns and predictive accuracies for various strategies

\begin{tabular}{|c|c|c|c|c|c|c|c|}
\hline \multirow{3}{*}{$\begin{array}{l}\text { Timing } \\
\text { strategy }\end{array}$} & \multirow{3}{*}{$\begin{array}{l}\text { Review } \\
\text { period }\end{array}$} & \multicolumn{3}{|c|}{ Possible returns } & \multicolumn{3}{|c|}{ Predictive accuracies to beat market } \\
\hline & & \multicolumn{2}{|c|}{ Predictive accuracies } & \multirow{2}{*}{$\begin{array}{l}\text { Insurance / } \\
\text { speculation }\end{array}$} & \multirow{2}{*}{$\begin{array}{l}\text { Sure } \\
\text { gain }\end{array}$} & \multirow{2}{*}{$\begin{array}{l}\text { Sure } \\
\text { loss }\end{array}$} & \multirow{2}{*}{$\begin{array}{l}\text { Equal } \\
\text { chance }\end{array}$} \\
\hline & & $100 \%$ & $0 \%$ & & & & \\
\hline & Annual & 21.2 & 3.2 & & 63.3 & 21.5 & 38.3 \\
\hline \multirow[t]{3}{*}{ Traditional } & Quarterly & 26.2 & -55 & & 82.5 & 20.2 & 50.9 \\
\hline & Monthly & 34.1 & -19.4 & & 86.2 & 30.5 & 61.4 \\
\hline & Annual & 14.2 & 100 & 14.2 & 56.2 & 0.3 & 0.6 \\
\hline \multirow[t]{3}{*}{ Bear strategy on index } & Quarterly & 23.4 & 8.0 & 20.3 & 73.7 & 2.0 & 5.0 \\
\hline & Monthly & 29.8 & -22 & 15.0 & 76.5 & 10.5 & 37 \\
\hline & Annual & 21.8 & 7.0 & 13.8 & 39.9 & 9.0 & 18.7 \\
\hline \multirow[t]{2}{*}{ Bull strategy on index } & Quarterly & 27.8 & 7.8 & 20.1 & 39.4 & 2.7 & 6.7 \\
\hline & Monthly & 33.3 & -0.9 & 14.9 & 61.7 & 14.5 & 33 \\
\hline \multirow[t]{2}{*}{ Bear strategy on future } & Quarterly & 26.5 & 8.8 & 23.8 & 76.1 & 1.5 & 3.0 \\
\hline & Monthly & 34.0 & -3.0 & 20.2 & 73.2 & 10.3 & 32.2 \\
\hline \multirow[t]{2}{*}{ Bull strategy on future } & Quarterly & 22.6 & 5.1 & 11.9 & 64.4 & 16.5 & 34.3 \\
\hline & Monthly & 31.5 & -6.2 & 8.1 & 71.8 & 24.4 & 46.3 \\
\hline \multicolumn{8}{|c|}{ The buy and hold return for the ALSI over the study period was $10.2 \%$} \\
\hline The buy and hold return & for T-bills c & tudy pe & was 15.1 & & & & \\
\hline
\end{tabular}

accuracies similar to those found by Waksman et al. (1997) would have been required. This may indicate that success of a traditional timing strategy may be less dependent on how the market performs over a period of time and more dependent on predicting market swings. for traditional timing.

The results from varying the review periods are similar to previous studies done by Jeffrey (1984), Firer et al. (1987) and Waksman, Sandler, Ward \& Firer (1997). Shortening the review period has the effect of achieving higher returns for the perfect timers but greater losses for the incompetent timers.

\section{(b) Option timing}

In all cases the returns from option timing, during the bear period studied, were less than those found in prior research, when the market was bullish. This is because there are very few periods when the market had the large positive upturns that help boost returns.

At the $100 \%$ accuracy level bull timing yields a higher return than bear timing. The reason for this is because the underlying asset for bull timing (Treasury bills) had a $4.9 \%$ return 'advantage' over the underlying asset for bear timing (the index). Also when perfect bear timers predict a market downturn they will purchase put options to maintain their wealth for the period. However perfect bull timers would merely sit with the cash portfolio and grow their wealth from the cash instruments. Thus when the market is predominately bearish the bull timers' wealth will increase relative to the bear timers, who are merely maintaining their wealth net of the cost of the put purchased. Thus there is a clear advantage for the bull timer during a bear market.

At the other end of the spectrum, with 100\% inaccurate timing, this pattern changes and it appears that bear timing may have a slight advantage. This is because the incorrect bull timers would have purchased many more options than the incorrect bear timers, due to the market being bearish. thus contributing to the poor performance of bull timing. Also the call options are more expensive than the puts.

However in all cases the required predictive accuracies were far lower than in past research. Most notably are the low accuracies needed for bull timing to beat a buy-and-hold strategy. For bull timing only $61.7 \%$ accuracy is required using monthly review periods and a remarkably low $39.4 \%$ accuracy is required for quarterly review periods. Thus one could conclude that bull market timing during a bearish market may be a viable strategy. The reason for this is that the return from the Treasury bills gave the bull timers an extra $4.9 \%$ over the market before any timing decisions had to be made. Thus the bull timers had a cushion in which to make incorrect decisions yet still beat the market.

For bear timing the required accuracies are higher than needed for bull timing but still lower than those required during a bull market. One reason is the poor performance of the underlying asset (index) held for bear timing. Another is that when interest rates are high, the cost of put contracts falls (put-call parity theorem) thus making the cost of an error less. Also there are less high market upturns in which increase returns. Figure 1 shows the results of bear and bull timing for monthly review periods.

As the review period is extended from monthly to quarterly to annual the same pattern as found in previous studies emerges. The shorter the review period the greater are the potential returns but also greater are the potential losses. Predictive accuracy required to beat the market also increases as the review period decreases.

\section{(c) Market timing using options on futures}

Waksman et al.'s (1997) study included the use of options on ALSI futures for market timing. The futures price was simulated since there was no actual data that could be used. In this study a long enough past history of futures prices could be obtained, so actual futures prices have been used to 


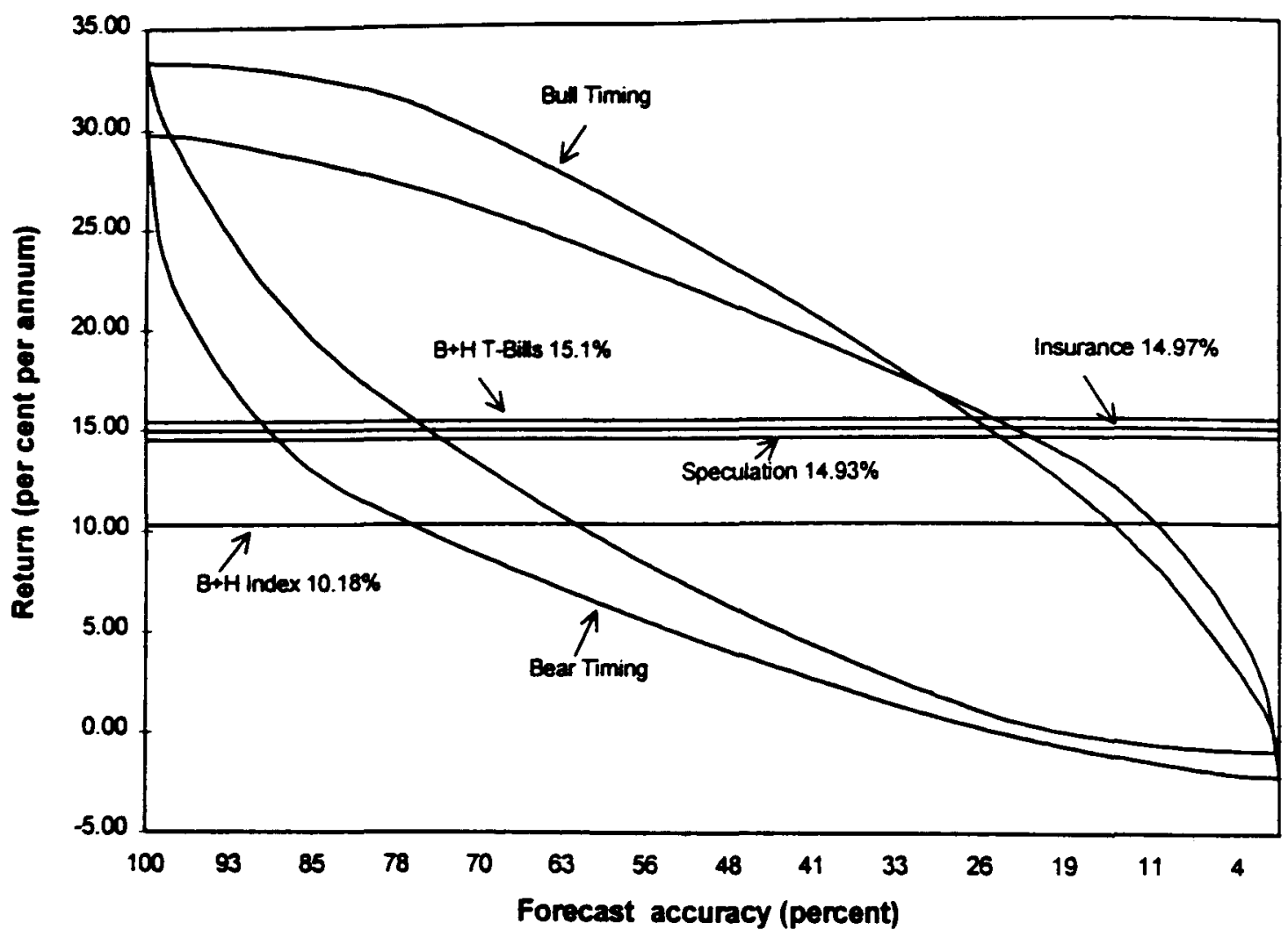

Figure 1 Forecast accuracy and returns for monthly option timing on the index

simulate the option prices. However, since futures contracts rarely trade longer than six months, it was not possible to simulate annual timing.

Again, because the market fell during this period, it had a profound effect on the results. During a bear market, an index's futures contract is likely to finish with its exercise price higher than the final spot price. Thus call options on the future will end up out of the money at expiration more often than expected. On the other hand, the put options end up in the money more often than usual.

This has the effect of making bear timing using the option on the future more profitable than bear timing using the option on the index, with maximum possible returns for perfect timing increasing by $3-4 \%$. For the incompetent timer there is very little difference in the returns since the cost of making a mistake is roughly the same regardless of the option chosen For bull timing there is the reverse effect. Timing using options on futures is less profitable for the perfect timer than options on the index, the difference being of the magnitude of $3-5 \%$.

For bear timing there appears to be very little difference, when moving from options on the index to options on the future, between the predictive accuracies needed to beat the market. However for bull timing there was a noticeable increase required in the predictive accuracies as the investor moved from options on the index to options on the future. This is because, for the bull timer, fewer of the option contracts will expire in the money, thus increasing the need to be correct more often in order to beat the market. This is graphically denoted by a downward shift in the 'football' causing the 'buy-and-hold the index' line to intersect at a higher predictive accuracy.

\section{(d) Market speculation and portfolio insurance}

In all cases, except for bull timing using options on the future, both market speculation and portfolio insurance outperformed the market. For market speculation the underlying asset (Treasury bills) again helped this strategy to beat the market despite the fact that the call options were not being exercised as frequently as under a bullish market. As for portfolio insurance, the put options were exercised more often than expected because the market was predominately bearish, thus leaving the put options habitually in the money.

As for speculation using options on the future, these options did not often expire in the money, for reasons previously stated. This had the effect of eroding returns from the cash portfolio as the premium costs could not be recovered from the few profitable options.

A surprising result was that quarterly speculation and insurance typically had returns $5 \%$ higher than annual or monthly speculation and insurance. It was noted that the quarterly option premiums were typically twice the value of the monthly premiums yet the market traded three times longer thus making a 'cheaper' option for this strategy. This may possibly explain the result obtained.

\section{Conclusions}

This study has shown that a perfect market timer will always beat the market regardless whether the market is bullish or bearish. In comparing to past research, it appears that the perfect timer would do better under bullish conditions than bearish conditions. The best of the options strategies tested would be bull timing using options on the index in order to have the returns assisted by the high return of the cash instruments during the bear market. The worst strategy to 
have employed would have been bear timing using options on the index since this portfolio had a poor performing underlying asset (index). Under all strategies the shorter the review period the greater the retums. but the predictive accuracies are also raised.

The bear market had a profound effect on the required predictive accuracies needed to beat buying and holding the market. For bull timing using options on the index, required predictive accuracies of only about $40 \%$ annual and quarterly timing and $61 \%$ for monthly timing were needed to beat the market. Thus one could conclude that having a strong underlying asset that provides a return greater than the market makes this strategy a lucrative one.

The results of bear timing using options on the index showed that when the underlying asset does not outperform the market then predictive accuracies in the order of $75 \%$ are required to beat the market. This is a fairly demanding level of predictive ability.

As for market timing using options on the index future, this study clearly showed that bull timing was not as profitable as bear timing. However bear timing did require slightly higher predictive accuracies.

Under bearish conditions both market speculation and portfolio insurance out performed the buy-and-hold strategy. This shows that these strategies are profitable under the correct market conditions. Also, due to the fact that there is unlimited upside potential and limited downside risk, these strategies may indicate that the risk profile of such strategies might be more favourable than the risk profile of the market itself. Further research in this area is required to confirm this.

In summary, when the market is bearish, there exists a real chance of bettering the buy-and-hold strategy for bull timers. The shorter the review period the greater the potential returns at marginally higher predictive accuracies. Bear timers, however, still require superior forecasting ability to better the market. Market speculation and portfolio insurance are also viable strategies and are relatively easy to implement practically.

\section{References}

Brenner. M. 1983. Option pricing theory and applications. Lexington. Massachusetts: Lexington Books.

Chua. J.H. Woodward. R.S. \& To. E.C. 1987. Potential gains from stock market timing in Canada. Financial Analysts Journal. SeptOct: $50-56$.

Droms, W.G. 1989. Market timing as an investment policy. Financial Analysts Journal. Jan-Feb: 73-77.

Firer. C. Gray. P. Sandler, M. \& Ward. M. 1996. Market timing and unit trusts: can you beat the market? South .African Journal of Business .Management. 27(3): 58-64.

Firer. C. Sandler. M. \& Ward. M. 1992. Market timing revisited. Invesiment Analysts Journal. 35: 7-13.

Firer. C. Ward. M. \& Teeuwisse, F. 1987. Market timing and the JSF. Investment Analysts Journal, 30: 19-31.

Gemmill, G. 1993. Option pricing an international perspective. New York: McGraw-Hill

Hanson. H.N. 1984. Portfolio insurance. New York: McGraw-Hill.

Jeffrey, R.H. 1984. The folly of stock market timing. Harvard Business Review, Jul-Aug: 102-110.

Kester, G.W. 1990. Technical notes - market timing with small versus large-firm stocks: potential gains and required predictive ability, Financial Analysts Journal, Sep-Oct: 63-69.

Sharpe, W.F. 1975. Likely gains from market timing. Financial Analysts Journal, Mar-Apr: 60-69.

Treynor, J.L. \& Mazuy, K.K. 1966. Can mutual funds outguess the market? Harvard Business Review. Jul-Aug: 131-136.

Waksman, G. Sandler. M. Ward. M \& Firer. C 1997. Market timing on the J.S.E. using derivative instruments. Omega. 25(1): 81-91. 